\title{
Task Variation and Mental Models Divergence Influencing the Transfer of Team Learning
}

\section{Andra F. Toader' and Thomas Kessler ${ }^{2}$}

\begin{abstract}
We investigate how teams develop and transfer general problem-solving skills across two ill-structured problems. We draw on cognitive flexibility theory in the instructional literature and propose that teams will achieve a higher performance on a novel task or transfer when they receive an external task intervention (i.e., task variation) and when the internal mechanisms (i.e., divergent mental models) are developed to make sense of the external intervention. To test these predictions, we designed a longitudinal experiment with 17 student teams that encountered task variation during their work on an initial task. Consistent with our predictions, we found that teams that experienced variations and whose mental models diverged during their work on an initial task achieved higher performance on a novel task than teams that experienced variation and whose mental models converged. Implications for the transfer of learning in teams on ill-structured problems are discussed.
\end{abstract}

\section{Keywords}

cognitive flexibility, transfer of learning, teams, mental models, task variation

\footnotetext{
'University of Konstanz, Kostanz, Germany

${ }^{2}$ Friedrich Schiller University, Jena, Germany
}

\section{Corresponding Author:}

Andra F. Toader, Department of Politics and Public Administration, Chair for Organizational Studies, University of Konstanz, Universitätsstrasse 10, 78457 Kostanz, Germany.

Email: andra.toader@uni-konstanz.de 
Individuals and groups engage in problem-solving behavior in educational, social, and workplace settings. Most of the human activity is focused on solving ill-structured problems, which are problems with unclear initial states or goals and ill-defined constraints (Jonassen, 1997). Medical, advertisement, and research and development are just some of the domains where ill-structured problems are frequent. Problem-solving is a permanent activity such that we frequently have to transition from work on one ill-structured task to the work on another ill-structured task (e.g., Jonassen, 1997; Spiro, Vispoel, et al., 1987). In this process, it helps if we are able to use lessons learned in one context to solve a problem in another context (e.g., Cramond, Martin, \& Shaw, 1990). This has been defined as transfer, and it is a fundamental building block of human learning (e.g., Cormier \& Hagman, 2014). Some authors suggest that transfer is often difficult to accomplish in that content knowledge and skills are not transferred across tasks (e.g., Detterman \& Sternberg, 1993). Meta-analytic evidence, however, shows that transfer can be achieved (e.g., Blume, Ford, Baldwin, \& Huang, 2010). However, most of this research studies transfer in individuals (Baldwin \& Ford, 1988; Blume et al., 2010; Burke \& Hutchins, 2007).

Our society has become ever more reliant on teams to solve problems in social, educational, and organizational settings (Kozlowski \& Bell, 2013; Mathieu, Maynard, Rapp, \& Gilson, 2008). Collaborative problem-solving models rest on the assumption that problem-solving is best carried out by teams who have higher processing capacity and construct higher quality mental models (e.g., Kirschner, Paas, \& Kirschner, 2009). However, we do not know much of how teams solve ill-structured problems and much less so about how they transfer problem-solving skills from one problem to another. This is our aim in this study. Using individual-based theories of learning on ill-structured problems (Spiro, Vispoel et al., 1987), we develop a model of transfer of learning on ill-structured problems at the team level of analysis. As problem-solving skills have become fundamental for skilled employment (Ederer, Nedelkoska, Patt, \& Castellazzi, 2015), our model adds explanatory power to the prediction of these skills and has practical implications.

We argue that developing transferable problem-solving skills (De Corte, 1990; Fischer \& Neubert, 2015) depends on two mechanisms. The first mechanism is external and refers to how the learning task is structured. Here, we draw on the cognitive flexibility theory (CFT) and advance that learning of general problem-solving skills on ill-structured tasks is enhanced if people have the opportunity to see the multifaceted nature of the task (Spiro, Coulson, Feltovich, \& Anderson, 1988; Spiro, Vispoel, et al., 1987). To demonstrate this, we introduce task variation during the teams' work on an initial ill-structured task. Task variation represents changes in the content, structure, or context of the problem 
(Hesketh, 1997; Schmidt \& Bjork, 1992). According to CFT, variation should lead to a crisscrossing of the task space from different vantage points which should enable members to grasp its multidimensional character (Spiro, Coulson et al., 1988; Spiro, Vispoel, et al. 1987).

The second mechanism is internal and refers to members' representation of the task conditions that they are experiencing. Here, we draw on mental models theory (e.g., Gentner \& Stevens, 1983; Johnson-Laird, 1983) to argue that task variation brings to the surface new task meaning. For these meanings to be used in the development of general problem-solving skills, they have to be represented cognitively (e.g., Van Boxtel, Van der Linden, \& Kanselaar, 2000). As the task is multifaceted, these cognitive representations should become more divergent over time to grasp the multiple facets of the task (Spiro, Vispoel et al., 1987). As such members must experience task variation (external mechanism) that brings to light different task meanings, and then their mental models must diverge (internal mechanism) to grasp those multiple meanings. The convergence of these two factors should lead to the development of general problem-solving skills, which enhance performance on a novel ill-structured task.

Our work contributes to research on problem-solving on ill-structured tasks in three fundamental ways. First, we contribute to the literature on illstructured problem-solving transfer in teams (e.g., Hargadon \& Bechky, 2006). Teams are prevalent in contexts where transfer of ill-structured problem-solving skills is needed (Paulus \& Nijstad, 2003). For example, design teams are tasked with the development of multiple novel products, or task forces are tasked with the development of solutions for different organizational problems. While we know that these teams need general problem-solving skills, which can aid their efforts across contexts, we do not know the mechanisms that support the development of these general problem-solving skills (Skilton \& Dooley, 2010). By proposing two factors that undergird this process, one external and one internal, we provide a model for fostering problem-solving skills development. In addition, we provide one of the few models in the organizational literature that deals with transfer at the team level, as opposed to the individual level (e.g., Chen, Thomas, \& Wallace, 2005; Lewis, Lange, \& Gillis, 2005; Schilling, Vidal, Ployhart, \& Marangoni, 2003). As teams have become the standard of work, understanding what undergirds their continuous performance improvement should be fundamental (Mathieu et al., 2008).

Second, our model provides an integration of the problem-solving transfer literature at the individual and team levels of analysis. We demonstrate that it is useful and appropriate to use theories that have been developed to explain transfer at the individual level for explaining transfer at the team level. Third, 
our longitudinal design provides a more accurate test of the development of these mechanisms over time. In particular, we show that members' mental models have to diverge over time for them to understand the task and transfer those understandings to a new task. We thus show that the development of problem-solving skills is a long-term process which to our awareness has not been explored before in the literature.

\section{CFT}

CFT is a theoretical orientation to learning and instruction in ill-structured knowledge domains (Spiro, Vispoel et al., 1987). CFT focuses in particular on the application of knowledge to novel situations or to the transfer of learning as opposed to the reproduction of learned material. A main tenet of the theory is that the transfer of learning in ill-structured domains depends on cognitive flexibility. Cognitive flexibility refers to the way knowledge is represented on ill-structured problems. These problems admit alternative solutions and have vaguely defined or unclear goals and constraints, multiple solution paths, and multiple criteria for evaluating solutions (Jonassen, 1997). Cognitive flexibility then refers to the ability to represent the knowledge from different vantage points and to construct ad hoc new knowledge when it is needed (Spiro \& Jehng, 1990). It relies on the application of three main principles to learning situations: (a) to view learning as multidirectional and multiperspectival crisscrossing of cases and concepts that form complex domain landscapes, (b) to provide for the emergence of multiple mental models, and (c) to enhance the ability to assemble knowledge sources as or when required for a specific situation (Spiro, Coulson et al., 1988; Spiro, Vispoel et al., 1987; Spiro, Feltovich, Jacobson, \& Coulson, 1991). In this section, we discuss the first principle and in the second, the second principle.

Spiro, Vispoel et al. (1987) drew on the work of Wittgenstein (1953) and suggested that ill-structured problems can be viewed as a complex landscape. A complex landscape is formed of multiple dimensions often hidden from the eyes of the viewer which cannot be fully grasped at a single traversal of the landscape. Instead, to grasp the landscape, one must take multiple alternate paths through it to bring to the surface its different dimensions, which is referred to as crisscrossing. Like a complex landscape, an ill-structured problem has many facets which cannot be fully grasped at a single traversal of the problem space (e.g., Feltovich, Coulson, Spiro, \& Dawson-Saunders, 1992). Any one concept or dimension of the problem can take on different meanings as a function of the context, time, or location on the landscape under which it is analyzed. Therefore, the content of the problem must be revisited in different contexts, at different moments, and in different locations. This represents 
a nonlinear and multidimensional traversal of complex knowledge domains returning to the same place in the conceptual landscape at different times and coming from different directions (Spiro \& Jehng, 1990). This crisscrossing of the landscape should, according to CFT, make people more flexible in understanding and solving ill-structured problems and in transferring their understanding to new problems (Spiro, Coulson et al., 1988; Spiro, Vispoel et al., 1987). Typically, crisscrossing is induced in the CFT approach to instruction using hypertext, a method which presents, in a computer-based environment, complex cases from multiple vantage points, by defining nonlinear linkages between the cases (Spiro, Feltovich, et al., 1991).

There is evidence supporting the tenets of CFT. Spiro, Vispoel et al. (1987) showed that learners engaged in standard learning outperformed learners engaged in flexibility learning on reproductive memory test but the flexibility learning group outperformed standard groups on six different measures of transfer. Jonassen and Grabinger (1993) described several studies in which standard and flexibility groups did not differ on measures of reproductive memory, but the flexibility group performed better on measures of knowledge application and transfer. Jacobson and Spiro (1995) found that learners trained in standard learning had a higher performance on measures of reproductive memory, but that flexibility trained groups outperformed them on measures of transfer. This provides support for CFT and suggests that flexibility learning conditions engage the learners in transfer-oriented advanced knowledge acquisition.

Similar to CFT, Bransford, Franks, Vye, and Sherwood (1989) discuss the need for contrasts in ill-structured problem-solving. In perceptual learning, contrasting figures, such as two circles of different size and location in the background, side by side, act as a foil, highlighting the unique characteristics of each figure, and thus aiding noticing and differentiation. Contrasting figures on different features leads to different other features becoming salient, such as thickness or color of the line. In problem-solving, contrasting elements of problems can influence what particular features of the problem one notices and their interpretation. This can influence future problem-solving efforts, such as stating hypotheses and setting goals. Schwartz and Bransford (1998) found that students made the best predictions on a novel transfer problem when they learned using contrasting cases and when the general principle of the cases was explained to them.

\section{External Mechanism: Task Variation}

Building on this evidence from CFT and the contrasting cases approach, in this study, we induce the crisscrossing of the landscape using a technique 
aimed at promoting transfer at the individual and team level — task variation. Task variation refers to the introduction of variation in task content, context, sequence, or feedback during the learning of a task (Hesketh, 1997; Schmidt $\&$ Bjork, 1992). It emerged in the transfer of learning and training as a powerful technique to induce transfer on different types of tasks (e.g., Ivancic \& Hesketh, 2000; Kamouri, Kamouri, \& Smith, 1986; McDaniel \& Schlager, 1990). We advance that task variation can induce learners to crisscross the problem landscape. In particular, we argue that the introduction of task variation in the form of changed task requirements should lead the learners to reexamine the task at different times, from different vantage points which should bring to light the complexity and multifacetedness of the task (e.g., Gary, Wood, \& Pillinger, 2012; McDaniel \& Schlager, 1990). At each change introduced, the learners will traverse the same conceptual problem space from a different point, with different goals, and thus may bring to surface different meanings embedded in the task which were not available at previous traversals (Spiro, Vispoel et al., 1987). This is also in line with the contrasting cases principle because seeing the same concept in a different context should lead to a redefinition and thus enrichment of the concept (Schwartz \& Bransford, 1998). This enlargement of the problem space should provide the chance to problem solvers to observe regularities of the problem-solving process (e.g., discovering different vantage points) which could be useful when they transfer to a new problem-solving activity.

Based on the CFT and contrast theories (Bransford et al., 1989; Spiro, Coulson et al., 1988; Spiro, Vispoel et al., 1987), task variation illuminates different aspects of the task, in that the stimulus becomes defined in a field of alternatives. For example, an organizational problem related with company innovation can take on different meanings if it is analyzed in a context of competitor threat, new governmental regulations, or research and development employee turnover. A solution to the problem would likely require viewing the problem from different vantage points that can be brought to light through the introduction of variations. The CFT has been developed to explain individual-level knowledge acquisition, but we believe that the same processes operate at the team level. We believe this because the task and the task requirements are similar, so the processes should inherently be similar (Morris, Bransford, \& Franks, 1977). Therefore, considering the evidence accumulated so far on the relevance of cognitive flexibility techniques for advanced transfer of learning, we hypothesize as follows:

Hypothesis 1: Task variation experienced on an ill-structured problem will lead to higher performance transfer on a novel ill-structured problem. 


\section{Internal Mechanism: Mental Models Divergence}

We argued in the previous section that task variation permits the problem solvers to crisscross the problem space from different directions, timings, and vantage points, thus enabling them to discover the multifaceted and multidimensional nature of the problem. The second principle of CFT states that learners or problem solvers on ill-structured problems must form multiple mental models of the content that they are accessing (Spiro, Coulson et al., 1988; Spiro, Vispoel et al., 1987). Multiple mental models are central to CFT because ill-structured problems are best described as representing multiple truths. According to CFT, single interpretations of a problem are not false, but they are inadequate because they do not account for sufficient within and across problem variability (Spiro, Feltovich, et al., 1991).

The problem space is represented through multiple dimensions and their association. For example, innovation as an objective of a company may be linked with dimensions of the company's external or internal environment. The configuration of these dimensions or their association is not fixed. Their association is interpreted in the context in which the dimensions are considered (Spiro, Coulson et al., 1998). Cognitively, these dimensions of the problem space and their interrelationships are represented as concepts and clusters of concepts or interlinked concepts. These structured organizations of concepts in long-term memory are known as mental models. Mental models stand at the basis of naturalistic cognition in that they enable people to process information in a rapid and flexible manner, thereby enhancing the potential to understand and explain situations, objects, and environments (e.g., Johnson-Laird, 1983). At the team level, mental models represent organized knowledge structures of the team and task environment (Cannon-Bowers, Salas, \& Converse, 1993; Klimoski \& Mohammed, 1994). Consistent with our theory and objectives, in this study, we refer to members' mental models of the problem space or problem mental models (October, 1990).

As posited by CFT, the interpretation of the problem space is context bound. Imagine that you see the problem space in one context or from one vantage point. Here, different links among the dimensions are highlighted which cognitively amount to different links among concepts in a mental model. Now imagine that you see the same dimensions in a different context. Here, the problem space is restructured, and instead of the previously noticed links among problem space dimensions, new links will appear. This restructuring of the problem space also amounts to a cognitive restructuring, in that you form a new mental model to represent the new configuration of the problem space. For example, concepts may be unrelated in some contexts yet highly related in other contexts. Hence, by viewing the same dimensions in 
different contexts or against a different background, different relationships among the objective dimensions and among their cognitive representations as mental models will appear.

The problem space of ill-structured problems is vast and complex (e.g., Jonassen, 1997; Simon, 1977). As such, it cannot be completely known at the first traversal (Spiro, Coulson et al., 1988). It takes multiple traversals through the problem space to discover all those different contexts in which the dimensions and the relationships among them can be represented. In a team, members may start out with a more general representation of the problem space. As each of the members start to explore the problem space dimensions in different contexts, their mental models may diverge from each other (Hutchins, 1991). This process is assumed fundamental in CFT. A comprehensive understanding of the problem space requires a process of gradual divergence in mental models. Diverging means that members grasp the different relationships among the problem space dimensions highlighted by context (Jacobson \& Spiro, 1995). As such, effective teams should be those that explore those different contextual meanings brought to light by task variation.

We argue that it is the divergence between the mental models of the team members that enables them to grasp the multiple understandings of the task. It is possible and entirely likely that the individual's mental model will vary over time. However, we believe that the key is divergence or variation among the members. If, for example, the individual diverges from his or her previous understanding but diverges in the same direction as the other team members, then, as a whole the team has grasped no more than one new understanding of the task. This means that at each new traversal of the problem space, members may grasp a new interpretation of the problem space, but that interpretation is similar to those of the other members. We argue that this process of convergence should restrict members' attention to only one context of the problem which overall should limit how much of the complexity of the problem space they grasp. If, however, the individual diverges not only from his or her previous understanding but also from the understanding of the other team members, then, as a whole, the team has grasped as many novel understandings as there are members, which should enrich their repertoire. As such, we expect teams that encounter task variation and whose mental models diverge over time between members to be more efficient that teams whose mental models converge because they are able to grasp more interpretations of the problem space. We also expect this to be independent of individual-level considerations as only the team as a whole can grasp one or multiple interpretations of the problem. 
We note at this point that task variation provides the opportunity for this gradual discovery of the problem space through the divergence of mental models. The burden, however, is on the learner to take into account those contextual meanings and to create different mental models of the contextual meanings. Not all problem solvers that are exposed to variation benefit from it. They must actively explore the problem space dimensions in their different contexts and actively construct mental models of those contexts (Shapiro $\&$ Niederhauser, 2004). For example, Bendixen and Hartley (2003) found that learners made use of the hypermedia environment effectively and achieved transfer only when they had high epistemological beliefs. Schwartz and Bransford (1998) found that students made use of the contrasting cases intervention and achieved transfer on a novel task only if they were presented the principles of the task after contrasting the cases. As such, we expect that teams whose mental models diverge when encountering task variation will achieve higher performance on a novel task than teams whose mental models converge. This is because this capacity to diverge should transfer to a new task, enabling members that analyze the dimensions of that new task to consider it from different vantage points. In this case, mental models divergence should be a moderator of the effect of task variation on novel task performance.

Hypothesis 2: Mental model divergence will moderate the effect of task variation on transfer of learning such that the teams whose mental models diverge while they experience variations will have a higher transfer than teams whose mental models converge.

\section{Transfer}

We also discuss the notion of transfer. Transfer is a phenomenon involving change in the performance of a task as a result of the prior performance on a different task (Gick \& Holyoak, 1987). Transfer can be near or far (Detterman \& Sternberg, 1993; Salomon \& Perkins, 1989; Thorndike, 1923), on multiple dimensions (Barnett \& Ceci, 2002), and specific or general (e.g., Barnett \& Ceci, 2002; Detterman, 1993; Gick \& Holyoak, 1980). Near or far transfer refers to the situation of transfer. Near transfer involves transfer to a task with identical elements and in the same context as the learned task (Thorndike, 1923). Far transfer involves transfer to a task with new, different elements and in a different context (e.g., Fong, Krantz, \& Nisbett, 1986). Barnett and Ceci (2002) identify multiple dimensions of transfer: knowledge domain, physical context, temporal context, functional context, social context, and 
modality. Specific versus general transfer refers to how generally applicable the learned information is (Barnett \& Ceci, 2002). Specific transfer represents transfer of facts or procedures, therefore the transfer of knowledge content, while general transfer refers to the transfer of general skills, principles, or causal schemas (e.g., Fong et al., 1986; Gick \& Holyoak, 1980; Perkins \& Grotzer, 1997).

Here, we are looking at moderate transfer on multiple dimensions (see task description in the section "Method"). More importantly, we are not constructing transfer from the content perspective, that is, the ability to use content knowledge learned in one context to solve a new similar problem. But, we are looking at the transfer of problem-solving skills, which should generalize across problems (e.g., Billing, 2007; Cheng \& Hampson, 2008). In particular, the mechanisms described here should enable members to search for information (crisscrossing the landscape), to structure the task, and to create divergent mental models. It is not the same as transferring solutions or strategies from one task to the other because what was efficient in the first (which was product focused) may not be efficient in the second (which is service focused). Therefore, the two mechanisms that we explore here, one external and one internal, should enable people to develop general problem-solving skills for attacking new ill-structured problems. This also corresponds to the notion of skill generalization to novel tasks or contexts in the transfer of training literature (Baldwin \& Ford, 1988).

\section{Method}

\section{Sample}

To test the study hypotheses, we conducted a 2 (task variation/control, between subjects) x 2 (Phase 1/Phase 2, within subjects) longitudinal experiment. The study sample consisted of undergraduate and graduate students with a social sciences background of a public university in Germany, $N=51$, $57 \%$ males, $M_{\text {age }}=24.75(S D=3.30), M_{\text {academic semester }}=4.43(S D=2.63), 98 \%$ German nationality. Mean grade point average (GPA) for the past academic year was $2.09(S D=0.59)$ on a scale from 1 (excellent) to 6 (insufficient). Participants were randomly assigned to teams, and teams were randomly assigned to experimental conditions, forming nine three-person teams $(N=$ $27)$ in the control condition and eight three-person teams $(N=24)$ in the task variation condition. Participants were rewarded $€ 25$ for their participation in the study. 


\section{Procedure}

The study was advertised through messages posted on campus or in Internetbased discussion groups. Students registered by sending an email to the experimenter with their preferred participation time and dates, selected from a list of options. The study consisted of two phases, scheduled to take place 2 or 3 days apart. Group composition remained constant across phases. All teams in a study session were assigned to the same experimental condition. The experiment was completed in $2.5 \mathrm{hr}$ for Phase 1 and $1.5 \mathrm{hr}$ for Phase 2. After 20 min of reading the information, team members completed a background questionnaire and the mental models measurement (Time 1 mental models).

\section{Task}

The task of the study consisted of providing solutions to problems described in case studies. Case studies are short stories or simulations in a particular domain that describe complete, accurate, and clear issues, events, and characters (Stolovitch \& Keeps, 1991). Cases provide descriptions of a situation and what led to it, problems, resources and constraints on the solution, decisions made and actions taken, and outcomes (Prince \& Felder, 2006). Cases are frequently used in medical, legal, and business education to train students' practical skills. CFT relies mostly on case studies to train cognitive flexibility, thus our selection of case studies to represent the study task is in line with that paradigm. Students had to solve two case studies in two different sessions, through face-to-face communication.

The case studies were developed based on Harvard Business School case studies. We adjusted and extended the case studies to provide a realistic problem which participants could solve. Four graduate students who reviewed the case studies confirmed that they were relevant, realistic, and consistent. Using case studies, we also aim to contribute to an emergent literature exploring transfer and the role of CFT in business education (e.g., Lima, Koehler, \& Spiro, 2004).

Case study I. For Phase 1, the participants received a 2.5 page case study describing the structure, history, culture, products, market, competition, and problems of a company operating in the soft drinks industry. The noted problems referred to reduced product innovation, increasing competition, declining profits, and rigid organizational culture and structure. Each team was provided with a plan template, in which they had to complete the following solution-related information: improvement strategies, timeframe for strategy 
implementation, budget required to implement each strategy, and expected outcomes of implementing the strategies proposed. Teams were given a budget of $€ 100,000$ and a 2-year timeframe for defining their solutions. Participants had to split the budget among their strategies and to schedule their actions such as to fit the given intervals and resources. In addition, each team member received role-specific information consisting of sales graphs and charts, personnel and customer surveys, and product information. To design additional materials, we reviewed industry profitability information, industry-specific terminology, information about employment and employee relations in the industry, information about products, and information about the market including customers. The additional materials, which were equally split among the team members, consisted of two thirds unique information and one third common information, distribution which was aimed at enhancing communication and participation in the task.

Case study 2. The Phase 2 case study had similar structure and requirements as the Phase 1 case study but referred to an organization operating in the hospitality industry (i.e., a hotel chain). The company problems related to low service innovation, increasing competition, rigid organizational culture and structure, and decreasing profits. As for the first case, the teams had to specify their solutions in a plan template. They had available a fictional budget of $€ 1,000,000$ and a timeframe of 2.5 years to define their solutions. Common and unique role-specific information was equally split among the members.

According to the framework of Barnett and Ceci (2002), the two case studies are far on the knowledge content (i.e., one refers to product innovation and the other to service innovation), they are near on physical (same laboratory) and social context (same team members) and moderate on temporal context (separation between initial case study and second case study of 2-3 days). With respect to the generality of transfer, there were no specific strategies or knowledge that could be transferred between the two case studies. Rather, participants should have developed a general understanding of how to work on the case studies (i.e., crisscrossing, divergent mental models) and transfer these abilities to solve the new case study. As such, we explored general transfer on the second case study.

\section{Experimental Manipulation}

Teams in the task variation condition received task requirements changes at three equally spaced 15 -min intervals throughout their work on the first task in the first phase of the study, starting $20 \mathrm{~min}$ after work onset. These were 
different changes in the organizational environment (i.e., competitor threat, downsizing threat, and employee turnover) to which team members had to respond and incorporate into their plan. The order of the three changes was counterbalanced. Members had $3 \mathrm{~min}$ to read the changes individually. They completed the second, third, and fourth mental models assessment after reviewing the first and second change, and at the end of the task, respectively (Time 2, Time 3, and Time 4 mental models). Teams assigned to the control condition did not experience task requirements changes, but they completed the mental models questionnaires at the same times as teams in the experimental condition.

\section{Measurement}

Mental models. We based our measurement of mental models on research on knowledge structures on transfer of training (Goldsmith \& Kraiger, 1997) and on team mental models literature (e.g., Mathieu, Heffner, Goodwin, Salas, \& Cannon-Bowers, 2000). Therefore, we used structural representations. Structural representations are formed by defining a list of key task concepts and then organizing these concepts in association matrices that the participants rate pairwise. This corresponds to our conceptualization of mental models as representing cognitively the dimensions of the problem space and the interrelationships among them. We defined the list of task terms by exploring in depth the case studies and the industry and scientific-related literature. Participants rated 11 task-related items organized in $10 \times 11$ association matrices. The following items were used: "Extend product distribution opportunities," "Product improvement and innovation," "Improve product marketing," "Employee training and development," "Changing the company structure and culture," "Extend customer segment," "Increase customer loyalty," "Close down product lines," "Financial problems-stagnant profit," "Competitive business environment," and "Company downsizing."

Participants rated the relationship between each item and all the other items on a 1 (unrelated) to 7 (completely related) scale for a total of 55 ratings. Participants' mental models were analyzed using UCINET software (Borgatti, Everett, \& Freeman, 2002), which provides an index of convergence between two matrices: the quadratic assignment procedure (QAP) correlation (see Mathieu et al., 2000, for a similar procedure). In this case, each member's mental model at each time point was represented by an association matrix that was symmetric with each other member's mental model. QAP compares two association matrices or mental models and outputs an index of correlation ranging between -1 and +1 . When members have more convergent mental models, the correlation coefficient will be closer to +1 , while 
when they have more divergent mental models, the correlation coefficient will be closer to -1 . We compared the three members' mental models pairwise obtaining three correlation coefficients. Then, we averaged the correlation coefficients between their mental models at the team level to obtain an index of how convergent members' mental models were at the team level. We did this for each timepoint. Convergence scores ranged from .06 to .57 (Time 1), from .07 to .67 (Time 2), from -.04 to .55 (Time 3), and from -.07 to .55 (Time 4).

Performance. Based on other work (e.g., Bell \& Kozlowski, 2008), we conceptualized in this study the transfer of learning as performance obtained on the second task relative to performance on the first. The assessment of team performance was based on a rating scale developed by the first author drawing on the relevant literature on team innovation and project planning (e.g., Besemer \& O'Quin, 1999; Cropley \& Kaufman, 2012; Pinto \& Prescott, 1990; West, 2002). Specifically, each team's plan was rated on eight subdimensions represented by between two and nine items on a 7-point Likert-type scale (46 items in total), ranging from 1 (does not apply to the actions described in the plan) to 7 (applies to all actions in the plan). The subdimensions represented were as follows: efficiency, four items (e.g., "There is a detailed budget for the project."), relevance, five items (e.g., "Actions serve the purposes described in the plan statement and case description."), implementability, three items (e.g., "The actions, as they are specified in the plan, can be translated into realized actions, put into practical effect."), value, four items (e.g., "The extent to which actions add value more than if they were not implemented or beyond other actions."), impact, eight items (e.g., "The implementation of the actions proposed will place much demand on the organization."), originality, two items (e.g., "The extent to which the actions proposed are unique and elicit surprise on the part of the evaluator."), novelty, eight items (e.g., "The group approached the problem in a novel, imaginative, unpredictable, or innovative manner."), and outcomes, four items (e.g., "The outcomes are described in sufficient detail for the stakeholders to have a clear perspective on the areas that will be improved, how, and how much.").

Teams' Phase 1 and Phase 2 plans were rated separately by two trained raters on each of the subdimensions described above. Raters were blind to the study hypotheses and were not aware of the conditions in which teams participated. The raters received a $5 \mathrm{hr}$ theoretical and applied training in which they were familiarized with the definitions of the performance subdimensions and in which they applied the learning content by rating a set of sample performance plans available from the study pretest. The consistency of the ratings between the two raters was assessed using the intraclass correlation 
coefficient, ICC(1), which yielded the following inter-rater reliabilities: efficiency, .89, relevance, .89, implementability, .75, value, .86, impact, .83, originality, .80 , novelty, .65 , outcomes, .61 . The ratings assigned by each rater to each subdimension were combined (i.e., average efficiency based on Rater 1 and Rater 2 ratings). The aggregate subdimensions were submitted to exploratory principal component factor analysis with Varimax rotation to determine performance dimensionality. Three factors emerged explaining $79.22 \%$ of the scale variance. The first factor, performance efficiency, explained $36.28 \%$ of the scale variance and was loaded by the outcomes and efficiency $(\alpha=.74)$, the second factor, performance effectiveness, explained $30.39 \%$ of the scale variance and was loaded by the value, implementability, and relevance subdimensions $(\alpha=.75)$, the third factor, performance novelty, explained $12.55 \%$ of the scale variance and was loaded by the novelty, originality, and impact subdimensions $(\alpha=.71)$. Note that the impact subdimension crossloaded on both the efficiency and novelty factor but according to our conceptual definition and its inclusion as a facet of innovation in the literature (e.g., West \& Anderson, 1996), we retained it for the novelty factor. To obtain the final performance score, we used a procedure used in the team creativity literature (e.g., Zhou \& Oldham, 2001; see also Gilson, Lim, Litchfield, \& Gilson, 2015; Shalley, Zhou, \& Oldham, 2004 for further discussion on the measurement of creativity) and multiplied the three performance dimensions. According to this operationalization, high team performance would be obtained if members had high scores on all three performance dimensions. This is also in line with our focus on ill-structured tasks which subsume creative tasks (e.g., Mumford, Supinski, Baughman, Constanza, \& Threlfall, 1997). Finally, to obtain the performance transfer score, we applied the following well-established formula (Murdoch, 1957): Percentage of transfer $=([$ Performance Phase $2-$ Performance Phase 1] $/$ [Performance Phase $2+$ Performance Phase 1]) x 100.

\section{Manipulation Checks}

To determine whether the task manipulation was perceived as intended, team members were asked questions related to their level of perceived task complexity and perceived task uncertainty. Task complexity was assessed using a four item scale adapted from Maynard and Hakel (1997) answered on a 1 (totally disagree) to 7 (totally agree) Likert-type scale. Sample items are as follows: "This task required a lot of thought and problem-solving," "I found this to be a challenging task," $\alpha=.88, r_{\mathrm{WG}}=.86, \operatorname{ICC}(1)=.60$. Perceived task uncertainty was assessed using three items constructed for this study, measured on a 1 (does not apply) to 7 (applies to a large extent) rating scale: "Our 
task requirements changed many times during our performance," "We experienced major changes in the task requirements," "We expected our task requirements to change while we were working," $\alpha=.80, r_{\mathrm{WG}}=.71, \operatorname{ICC}(1)$ $=.57$. We expected no differences between teams on the complexity measure but significant differences on the uncertainty measure as changes and not task complexity constituted the manipulation of the study. The results of an independent samples $t$ test showed that participants in the task variation condition did not perceive a higher task complexity than participants in the control condition, $t(17)=.51, p<.62, M_{\text {task variation }}=4.89$ versus $M_{\text {control }}=4.66$, but that they perceived a higher task uncertainty than the participants in the control condition, $t(17)=2.56, p<.05, M_{\text {task variation }}=4.42$ versus $M_{\text {control }}=3.24$. These results suggest that our manipulation was effective. Because task complexity and task uncertainty may be related with the experimental conditions as well as determine the mental models characteristics, we controlled for both in the analysis.

\section{Analysis Strategy}

We hypothesized that the development of mental models over time will moderate the effect of task variation on the transfer of learning. We operationalized the development of mental models as the slopes of the mental models coefficients obtained through a random coefficients-latent growth model (RCM; Raudenbusch \& Bryk, 2002). More specifically, we followed a procedure employed by Chen, Ployhart, Thomas, Anderson, and Bliese (2011), and we retained the linear time growth empirical Bayes estimates obtained in the RCM model of mental models divergence regressed on time as mental models change predictors. The empirical Bayes estimates yield more precise estimates than the ordinary least squares (OLS) estimates obtained from the regression of each group's outcome on the predictors (Cohen, Cohen, West, $\&$ Aiken, 2003). These coefficients represent changes in mental models that are allowed to vary across groups and which can thus, be used in ordinary correlation or regression analysis conducted at the group level. The analysis of mental models change over time confirmed that mental models developed over the four timepoints; therefore, the use of this procedure is justified $\left(\gamma_{\text {time }}\right.$ $=-.04, p<.01$; Bliese \& Ployhart, 2002). More specifically, mental models of teams in the control condition diverged over time $\left(M_{\text {time 1 }}=.33, S D=.06\right.$; $M_{\text {time 2 }}=.25, S D=.10 ; M_{\text {time 3 }}=.22, S D=.19 ; M_{\text {time 4 }}=.17, S D=.13$ ) while mental models of teams in the task variation condition converged between Time $1(M=.30, S D=.13)$ and Time $2(M=.33, S D=.20)$ and then they diverged $\left(M_{\text {time } 3}=.27, S D=.18 ; M_{\text {time } 4}=.25, S D=.21\right)$. The slopes of the RCM model represent mental models convergence over time. To represent 
Table I. Means, Standard Deviations, and Correlations Among the Study Variables $(N=17)$.

\begin{tabular}{lrrrrrrrrrrr}
\hline Variable & $M$ & SD & I & 2 & 3 & 4 & 5 & 6 & 7 & 8 & 9 \\
\hline I. Task variation & 0.47 & 0.51 & - & & & & & & & \\
2. Performance Phase 2 & 85.90 & 25.30 & .27 & - & & & & & & \\
3. Performance Phase I & 107.30 & 29.43 & .30 & $.82 * *$ & - & & & & & \\
4. Task complexity & 4.45 & 0.58 & .29 & -.04 & .18 & $(.88)$ & & & & \\
5. Task uncertainty & 1.85 & 0.65 & -.44 & -.41 & -.33 & .02 & $(.80)$ & & & \\
6. Mental models TI & 0.20 & 0.10 & -.19 & .14 & .08 & .03 & .06 & - & & \\
7. Mental models T2 & 0.13 & 0.15 & .27 & -.03 & .22 & .44 & -.29 & .34 & - & \\
8. Mental models T3 & 0.07 & 0.18 & .13 & .09 & .18 & -.04 & .26 & .18 & .44 & - \\
9. Mental models T4 & 0.04 & 0.17 & .22 & .04 & .00 & -.09 & -.23 & .29 & $.62^{* *}$ & $.73^{* *}$ & -
\end{tabular}

Note. Alpha coefficients reported on the main diagonal. $* * p<.01$.

divergence, we recoded this variable such that higher scores represent increasing divergence over time while lower scores represent increasing convergence. To account for the low sample size, we report results at $p<.10$ significance levels.

\section{Results}

Means, standard deviations, and correlations among the variables are represented in Table 1 . As can be seen, task variation did not correlate significantly with mental models or with performance on the two case studies. Performance on Phase 1 correlated significantly with performance on Phase $2(r=.82, p<$ $.01)$. Mental models at Time 4 correlated significantly with mental models at Time $2(r=.62, p<.01)$ and Time $3(r=.73, p<.01)$. No other correlations were significant.

\section{Task Variation and Performance Transfer}

To determine whether teams in the task variation condition obtained a higher performance transfer, we conducted an analysis of variance with the experimental condition as a between-subjects factor and performance transfer as the dependent variable. The results of this analysis showed that teams that experienced variation did not achieve a higher performance transfer than teams in the control condition, $F(1,13)=.17, p=.68$. The differences between the means of the two conditions, however, were in the expected direction $\left(M_{\text {task variation }}=10.34\right.$ vs. $\left.M_{\text {control }}=12.47\right)$. Overall, these results do not support Hypothesis 1. 
Table 2. The Indirect Effect of Task Variation on Performance Transfer as Moderated by Mental Models Divergence $(N=17)$.

\begin{tabular}{|c|c|c|c|c|}
\hline \multirow[b]{3}{*}{ Predictors } & \multicolumn{4}{|c|}{ Performance transfer } \\
\hline & \multicolumn{2}{|c|}{ Step I } & \multicolumn{2}{|c|}{ Step 2} \\
\hline & $b$ & SE & $b$ & SE \\
\hline Task variation & .56 & 6.05 & -.51 & 4.75 \\
\hline Task uncertainty & -4.68 & 4.67 & $-7.39 * *$ & 3.79 \\
\hline Task complexity & -6.07 & 4.60 & $-7.04^{* *}$ & 3.62 \\
\hline Mental models divergence & .39 & 3.06 & $-6.23 * *$ & 3.42 \\
\hline Task variation $\times$ Mental models divergence & & & $12.57^{*}$ & 4.63 \\
\hline$R^{2}$ & .28 & & .61 & \\
\hline$F$ & .98 & & $7.36 *$ & \\
\hline
\end{tabular}

Note. Values represent unstandardized betas.

$*_{p}<.05$. ** $p<.10$.

\section{The Moderation of Task Variation by Divergent Mental Models}

Before conducting the analyses, we standardized the mental models divergence variable (Aiken \& West, 1991). To determine whether task variation would lead to higher transfer performance when the teams developed more divergent mental models (Hypothesis 2), we performed a moderated regression analysis. In the first step, we entered the control variables, task complexity and task uncertainty, the experimental condition (coded as 0 for teams in the control condition, 1 for teams in the task variation condition), and mental models divergence. At step two of the analysis, we entered the cross-product of the experimental condition with the mental models divergence variable. The hypothesis would be supported if the change in $R^{2}$ at the introduction of the interaction term is significant. As can be seen in Table 2, at the first step of the analysis, no variables had a significant effect. The model explained overall $R^{2}=.28$ of the variance, $F(4,14)=.98, p=.46$. At step two of the analysis, the introduction of the interaction between task variation and mental models divergence explained an additional $R^{2}=.32$ of the variance, $F(1,14)$ $=7.36, p<.05$. The coefficient of the interaction was significant, $b=12.57$, $p<.05$.

We represent graphically this interaction according to the recommendations of Aiken and West (1991) in Figure 1, at $-/+1 S D$. Teams in the task variation condition had a lower performance when their mental models converged, simple slope $=-34.88, t(11)=1.60, p=.14$, although not significantly so, while they had a higher performance when their mental models diverged, 


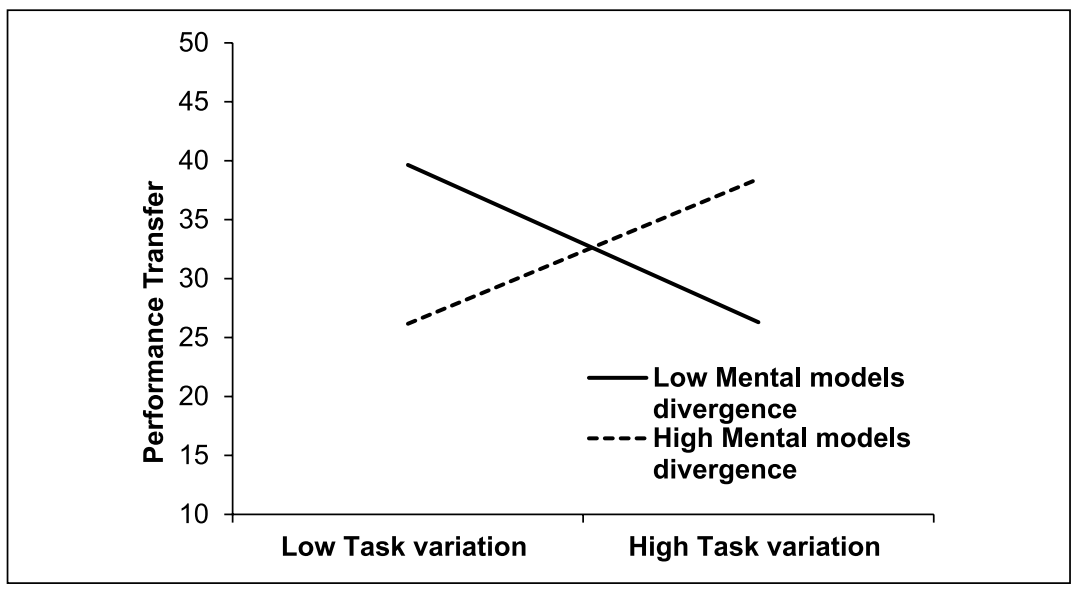

Figure I. The effect of the interaction between the experimental condition and mental models divergence on performance transfer.

Note. Low task variation $=$ Teams in the control condition. . High task variation $=$ Teams in the task variation condition. Low mental models divergence $=$ Mental models that converged across four measurement points. High mental models divergence $=$ Mental models that diverged across four measurement points.

simple slope $=12.06, t(11)=2.61, p<.05$. To determine the extent to which divergence versus convergence enhance performance in the task variation condition, we applied the Johnson-Neyman technique to determine significance regions for the interaction (see Appendix). Results showed that when mental models divergence is low, evaluated at $-1.61 S D$, teams will attain a lower performance transfer $(p=.05)$ while when mental models divergence is high, evaluated at $1.54 S D$, teams will attain a higher performance transfer $(p<.05)$. In other words, if teams' mental models converge instead of diverging in the task variation condition, they will attain a lower performance transfer. Similar analyses performed on the performance of teams in the control condition showed a reversed pattern of results, with higher performance when mental models converged and lower performance when mental models diverged over time. These results provide support for Hypothesis 2.

\section{Discussion}

In this study, we investigated the transfer of learning in teams using the CFT. We advanced based on CFT that to achieve transfer on a novel problem, teams have to benefit from two mechanisms. The first mechanism, external, referred to the structure of the task. CFT proposes that tasks that 
enable problem solvers to crisscross the problem landscape will lead to higher transfer. We introduced a task variation condition to enable our participants to crisscross the problem landscape. The second mechanism, internal, referred to the cognitive representations that participants developed while they were solving the ill-structured problem. CFT proposes that tasks that encourage crisscrossing will lead to the highest amount of transfer when the problem solvers develop divergent mental models during their exploration of the problem space. We found support for these two mechanisms in conjunction. We did not find that task variation alone led to higher transfer.

Our reasoning supports this, however, as we are arguing that task conditions may not be sufficient if learners do not also take advantage of those conditions by developing flexible knowledge structures (e.g., Alfieri, Brooks, Aldrich, \& Tennenbaum, 2011; Kirschner, Sweller, \& Clark, 2006; Mayer, 2004). For example, learners may notice different principles that hold across tasks but if they do not incorporate them in their mental models, they will not achieve transfer. Consistent with this, we found that teams that solved a problem on which they encountered task variation and whose mental models diverged during their work on this problem achieved a higher transfer. In other words, task variation illuminated the diverse relationships among the problem space dimensions which in turn were instrumental in problem-solving when members managed to grasp them cognitively by forming divergent mental models. This provides support for the tenets of CFT and suggests that it may be successfully applied to the team level of analysis.

However, it may be possible that there are multiple ways of considering the complex problem space. More specifically, our results show that similar levels of performance may be achieved by teams that do not experience variation and that develop more convergent instead of more divergent mental models. This attests to the equifinality of problem-solving (Jonassen, 1997), where multiple strategies to approach the problem-solving process may apply. Contrarily, it may also be possible that task variation and mental models divergence offer long-term advantages (e.g., McDaniel \& Schlager, 1990; Paas \& Van Merriënboer, 1994). They constitute abilities that transfer to different tasks, more distal on the transfer dimensions (Barnett \& Ceci, 2002) and that may account for the attainment of high performance over the longterm (Skilton \& Dooley, 2010). Our tasks in this study were related and moderately similar on various transfer dimensions. However, research employing more distally related tasks may be better able to distinguish the effectiveness of task variation as a mechanism influencing transfer (McDaniel \& Schlager, 1990; Paas \& Van Merriënboer, 1994). 


\section{Implications}

Our work has several implications for theory. First, we investigated transfer of learning on ill-structured problems in teams. The research that exists tends to focus on tasks situated more at the well-defined end of the continuum (e.g., Schilling et al., 2003). However, teams in current educational and business environments frequently deal with ill-structured problems which make understanding how they transfer general skills across problems a requirement. For example, project or product development teams frequently must shift between working on one ill-structured project or product to working on another ill-structured project or product. We do not understand, however, how these teams manage to transfer understandings, principles, or general skills between projects. Our study covers this gap and provides an initial model on which future research could build. For example, there is a lot of work on team creativity which could benefit deeper understanding on how to achieve transfer across creative tasks in teams.

Second, we generalized individual-level literature on learning and transfer to the team level of analysis. We suggested that the CFT described general processes which could also operate in teams. As such, this theory could also be instrumental for understanding how transfer unfolds in teams. Indeed, our work suggests that the tenets of CFT, crisscrossing of the problem landscape, and multiple representations, operate similarly at the team level and at the individual level. This model could prove useful for future research focusing on transfer of learning in teams. Despite being on the front page of research needs (e.g., Baard, Rench, \& Kozlowski, 2014), transfer of learning in teams is under-researched. Therefore, using models developed in other literatures or building new models based on these could improve our understanding.

Third, our contribution is also methodological. We proposed that teams should continue to improve their understanding throughout the task by forming more divergent mental models. This development would suggest that efficient teams make the best use of their contextual and cognitive resources. While knowledge development is inherent in a learning context, few models actually explore the development of cognition over time (e.g., Kraiger, Salas, $\&$ Cannon-Bowers, 1995), much less so at the team level. As such, our model suggests that we should also pay consideration to developmental aspects and view learning and transfer as a long-term phenomenon.

Our model also has implications for practice. It suggests that to achieve transfer on ill-structured tasks, conditions should be embedded in the task that enables members to grasp its meanings and develop general problemsolving skills. As an alternative to the more complex hypertext, variation could be introduced that illuminates the different meanings of the task that 
the instructor aims to emphasize. This type of event-based training has been used, for example, efficiently to train teams in the military domain (Oser, Gualtieri, Cannon-Bowers, \& Salas, 1999). However, we also emphasize that the task context by and of itself is not sufficient to enhance transfer. Instead, members should be supported in developing divergent mental representations of the conditions that they are experiencing. For example, at the introduction of a new event, the task could be paused and the different emergent interpretations explored. Furthermore, this process of developing divergent mental models could be made more explicit, for example, by asking members to engage in brainstorming on the meaning of the variations introduced or to issue task restatements (Baer, 1988; Scott, Leritz, \& Mumford, 2004).

\section{Limitations and Future Research Directions}

Our study has several limitations which need to be discussed. First, we relied on a student sample and a contrived task in testing the predictions. These factors may lessen the impact of the findings and preclude generalizations to real organizational samples and to more realistic operational environments. Nonetheless, a controlled setting enabled us to clearly disentangle the effects of the intervention and of mental models. We also assessed longitudinal performance by engaging teams in another task a few days after the first task. Real teams may rejoin to perform new tasks at different intervals which may affect their outcomes differently.

Our sample size was also small, which may affect the power of our results. To determine whether our study sample had sufficient power to detect the effects, we conducted post hoc power analyses. Results for Hypothesis 1 showed that our study had a power of .54 to detect an effect. This suggests caution in interpreting the finding regarding the effect of task variation. For Hypothesis 2, based on our effect size of .82, alpha probability level of .05 , and sample size of $N=17$, the power analysis indicated a power of .92 to detect the effect. We also note that statistical interactions are known for low statistical power (e.g., Aguinis, 1995; McClelland \& Judd, 1993) and that effect sizes as low as $2 \%$ to $3 \%$ can be considered practically significant. For example, for categorical variables, Aguinis, Beaty, Boik, and Pierce (2005) identified a median effect size of only .002 , but $72 \%$ of the moderator tests had power of .80 or greater to detect the effect. In this study, the interaction explained an additional $32 \%$ of variance in our dependent variable over and above the other variables in the analysis. Complemented by the post hoc power analysis, this lends some confidence to our results. Nevertheless, we do encourage future research to replicate these findings with larger sample 
sizes, especially with respect to the relationship between task variation and future task performance.

Another limitation is that we relied on newly formed or ad hoc teams in this study. Our theoretical arguments centered on the development of problem-solving skills in teams that can be transferred across tasks. If teams already exist, however, they may have already developed problem-solving skills for dealing with different types of problems and developing new skills may require novel interventions. As such, our findings may generalize most to newly formed teams in the process of developing problem-solving skills.

Several limitations related to our task design also deserve mentioning. First, we used individual-level theory and assumed that the relationships uncovered at the individual level will hold at the team level, for which we found support. However, we did not actually test whether these results hold across levels of analysis (i.e., by introducing an individual-level condition and comparing it with the team level). Future studies interested in the transfer of learning could compare both levels of analysis to determine whether the relationships hold across levels (e.g., Chen et al., 2005). Second, we assumed that during the learning of the first task, efficient teams will develop general problem-solving skills that would enable them to attack new problems. We did not however measure these general problem-solving skills which are implicit in our model but instead focused only on performance on the new task relative to the initial task. Future studies could measure these general problem-solving skills to determine whether the mechanisms that we proposed indeed influence their development (e.g., Greiff, Fischer, Stadler, \& Wüstenberg, 2015). Relatedly, we assumed that participants will develop general and not specific problem-solving skills, but our design did not differentiate these. Future designs should better control for these differences.

Third, participants did not receive performance feedback after their performance on the first task. Feedback could have enabled them to differentiate between effective and ineffective strategies and thereby enhance transfer to a new task (e.g., Alfieri, et al., 2011). Future studies therefore could also introduce a feedback condition. Fourth, we measured whether teams were able to develop more divergent mental models during their work on the first task. A stronger test of our model would have been provided by the actual manipulation of cognitive divergence which future studies could employ. Finally and directly related to the team literature, it would also be interesting to determine whether the skills developed are team specific or whether they can be transferred to other contexts, to other teams or for individual problem-solving (e.g., Laughlin \& Barth, 1981; Laughlin, Carey, \& Kerr, 2008; Laughlin \& Sweeney, 1977). 


\section{Conclusion}

This study showed that teams achieve higher transfer on ill-structured problem-solving tasks if they benefit an external task variation mechanism and an internal mental model divergence mechanism. Future work could further explore the transfer of learning in teams on ill-structured tasks by looking at additional mechanisms.

\section{Appendix}

Results of the Johnson-Neyman Procedure $(\mathrm{N}=17)$.

\begin{tabular}{lllllll}
\hline Team mental & & & & & & \\
models divergence & Effect & $S E$ & $T$ & $p$ & LLCI & ULCl \\
\hline-1.6093 & -20.7372 & 9.1667 & -2.2622 & .05 & -41.4811 & 0.0066 \\
-1.4517 & -18.757 & 8.5498 & -2.1939 & .0559 & -38.1048 & 0.5908 \\
-1.2942 & -16.7768 & 7.9521 & -2.1097 & .0641 & -34.7719 & 1.2183 \\
-1.1366 & -14.7966 & 7.3782 & -2.0054 & .0759 & -31.4931 & 1.8999 \\
-0.9791 & -12.8164 & 6.8342 & -1.8753 & .0935 & -28.2818 & 2.649 \\
-0.8215 & -10.8362 & 6.3278 & -1.7125 & .121 & -25.1556 & 3.4832 \\
-0.6639 & -8.856 & 5.8687 & -1.509 & .1656 & -22.1364 & 4.4245 \\
-0.5064 & -6.8757 & 5.4688 & -1.2573 & .2403 & -19.2514 & 5.4999 \\
-0.3488 & -4.8955 & 5.1421 & -0.9521 & .3659 & -16.5317 & 6.7407 \\
-0.1913 & -2.9153 & 4.903 & -0.5946 & .5668 & -14.0106 & 8.18 \\
-0.0337 & -0.9351 & 4.7649 & -0.1963 & .8488 & -11.7179 & 9.8477 \\
0.1238 & 1.0451 & 4.7366 & 0.2206 & .8303 & -9.6737 & 11.7638 \\
0.2814 & 3.0253 & 4.82 & 0.6276 & .5458 & -7.8822 & 13.9328 \\
0.439 & 5.0055 & 5.0096 & 0.9992 & .3438 & -6.3309 & 16.342 \\
0.5965 & 6.9857 & 5.2939 & 1.3196 & .2196 & -4.9941 & 18.9655 \\
0.7541 & 8.9659 & 5.6587 & 1.5845 & .1476 & -3.8394 & 21.7713 \\
0.9116 & 10.9461 & 6.0895 & 1.7975 & .1058 & -2.8341 & 24.7264 \\
1.0692 & 12.9263 & 6.5734 & 1.9665 & .0808 & -1.949 & 27.8017 \\
1.2267 & 14.9066 & 7.0996 & 2.0996 & .0652 & -1.1594 & 30.9725 \\
1.3843 & 16.8868 & 7.6592 & 2.2048 & .0549 & -0.4456 & 34.2192 \\
1.4904 & 18.2197 & 8.0513 & 2.2629 & .0499 & .0000 & 36.4395 \\
1.5419 & 18.867 & 8.2456 & 2.2881 & .0479 & 0.2077 & 37.5263 \\
\hline
\end{tabular}

Note. Team mental models divergence is represented through standardized scores. $\mathrm{LLCl}=$ lower level confidence interval; ULCI = upper level confidence interval.

\section{Authors' Note}

Andra F. Toader was at the Institute of Psychology, Friedrich Schiller University and the International Max Planck Research School, Jena, Germany on Adapting Behavior in a Fundamentally Uncertain World, when this research was conducted. 


\section{Declaration of Conflicting Interests}

The author(s) declared no potential conflicts of interest with respect to the research, authorship, and/or publication of this article.

\section{Funding}

The author(s) received no financial support for the research, authorship, and/or publication of this article.

\section{References}

Aguinis, H. (1995). Statistical power with moderated multiple regression in management research. Journal of Management, 21, 1141-1158. doi:10.1177/ 014920639502100607

Aguinis, H., Beaty, J. C., Boik, R. J., \& Pierce, C. A. (2005). Effect size and power in assessing moderating effects of categorical variables using multiple regression: A 30-year review. Journal of Applied Psychology, 90, 94-107. doi:10.1037/00219010.90.1.94

Alfieri, L., Brooks, P. J., Aldrich, N. J., \& Tenenbaum, H. R. (2011). Does discovery-based instruction enhance learning? Journal of Educational Psychology, 103, 1-18. doi:10.1037/a0021017

Baard, S. K., Rench, T. A., \& Kozlowski, S. W. (2014). Performance adaptation: A theoretical integration and review. Journal of Management, 40, 48-99. doi:10.1177/ 0149206313488210

Baer, J. M., Jr. (1988). Long-term effects of creativity training with middle school students. The Journal of Early Adolescence, 8, 183-193. doi:10.1177/ 0272431688082006

Baldwin, T., \& Ford, J. K. (1988). Transfer of training: A review and directions for future Research. Personnel Psychology, 41, 63-105. doi:10.1111/j.1744-6570.1988. tb00632.x

Barnett, S. M., \& Ceci, S. J. (2002). When and where do we apply what we learn? A taxonomy for far transfer. Psychological Bulletin, 128, 612-637. doi:10.1037/00332909.128.4.612

Bell, B. S., \& Kozlowski, S. W. (2008). Active learning: Effects of core training design elements on self-regulatory processes, learning, and adaptability. Journal of Applied Psychology, 93, 296-316. doi:10.1037/0021-9010.93.2.296

Bendixen, L. D., \& Hartley, K. (2003). Successful learning with hypermedia: The role of epistemological beliefs and metacognitive awareness. Journal of Educational Computing Research, 28, 15-30. doi:10.2190/2Y7C-KRDV-5U01-UJGA

Besemer, S. P., \& O'Quin, K. (1999). Confirming the three-factor creative product analysis matrix model in an American sample. Creativity Research Journal, 12, 287-296. doi:10.1207/s15326934crj1204_6

Billing, D. (2007). Teaching for transfer of core/key skills in higher education: Cognitive skills. Higher Education, 53, 483-516. doi:10.1007/s10734-005$5628-5$ 
Bliese, P. D., \& Ployhart, R. E. (2002). Growth modeling using random coefficient models: Model building, testing, and illustrations. Organizational Research Methods, 5, 362-387. doi:10.1177/109442802237116

Blume, B. D., Ford, J. K., Baldwin, T. T., \& Huang, J. L. (2010). Transfer of training: A meta-analytic review. Journal of Management, 36, 1065-1105. doi:10.1177/ 0149206309352880

Borgatti, S. P., Everett, M. G., \& Freeman, L. C. (2002). UCINET 6 for windows: Software for social network analysis (Version 6.102). Harvard, MA: Analytic Technologies.

Bransford, J. D., Franks, J. J., Vye, N. J., \& Sherwood, R. D. (1989). New approaches to instruction: Because wisdom can't be told. In S. Vosniadou \& A. Ortony (Eds.), Similarity and analogical reasoning (pp. 470-497). New York, NY: Cambridge University Press. doi:10.1017/CBO9780511529863.022

Burke, L. A., \& Hutchins, H. M. (2007). Training transfer: An integrative literature review. Human Resource Development Review, 6, 263-296. doi:10.1177/ 1534484307303035

Cannon-Bowers, J. A., Salas, E., \& Converse, S. (1993). Shared mental models in expert team decision making. In N. J. Castellan Jr. (Ed.), Individual and group decision making (pp. 221-246). Hillsdale, NJ: Lawrence Erlbaum.

Chen, G., Ployhart, R. E., Thomas, H. C., Anderson, N., \& Bliese, P. D. (2011). The power of momentum: A new model of dynamic relationships between job satisfaction change and turnover intentions. Academy of Management Journal, 54, 159-181. doi:10.5465/AMJ.2011.59215089

Chen, G., Thomas, B., \& Wallace, J. C. (2005). A multilevel examination of the relationships among training outcomes, mediating regulatory processes, and adaptive performance. Journal of Applied Psychology, 90, 827-841. doi:10.1037/00219010.90.5.827

Cheng, E. W., \& Hampson, I. (2008). Transfer of training: A review and new insights. International Journal of Management Reviews, 10, 327-341. doi:10.1111/j.14682370.2007.00230.x

Cohen, J., Cohen, P., West, S. G., \& Aiken, L. S. (2003). Applied multiple regression and correlation analysis for the behavioral sciences (3rd ed.). Hillsdale, NJ: Lawrence Erlbaum.

Cormier, S. M., \& Hagman, J. D. (Eds.). (2014). Transfer of learning: Contemporary research and applications. San Diego, CA: Academic Press.

Cramond, B., Martin, C. E., \& Shaw, E. L. (1990). Generalizability of creative problem solving procedures to real-life problems. Journal for the Education of the Gifted, 13, 141-155. doi:10.1177/016235329001300203

Cropley, D. H., \& Kaufman, J. C. (2012). Measuring functional creativity: NonExpert Raters and the Creative Solution Diagnosis Scale. The Journal of Creative Behavior, 46, 119-137. doi:10.1002/jocb.9

De Corte, E. (1990). Towards powerful learning environments for the acquisition of problem-solving skills. European Journal of Psychology of Education, 5, 5-19. doi:10.1007/BF03172765 
Detterman, D. K. (1993). The case for the prosecution: Transfer as an epiphenomenon. In D. K. Detterman \& R. J. Sternberg (Eds.), Transfer on trial: Intelligence, cognition, and instruction (pp. 1-24). Westport, CT: Ablex Publishing.

Detterman, D. K., \& Sternberg, R. J. (Eds.). (1993). Transfer on trial: Intelligence, cognition, and instruction. Westport, CT: Ablex Publishing.

Ederer, P., Nedelkoska, L., Patt, A., \& Castellazzi, S. (2015). What do employers pay for employees' complex problem solving skills? International Journal of Lifelong Education, 34, 430-447. doi:10.1080/02601370.2015.1060026

Feltovich, P. J., Coulson, R. L., Spiro, R. J., \& Dawson-Saunders, B. K. (1992). Knowledge application and transfer for complex tasks in ill-structured domains: Implications for instruction and testing in biomedicine. In D. A. Evans \& V. L. Patel (Eds.), Advanced models of cognition for medical training and practice (pp. 213-244). Berlin, Germany: Springer. doi:10.1007/978-3-662-02833-9_12

Fischer, A., \& Neubert, J. C. (2015). The multiple faces of complex problems: A model of problem solving competency and its implications for training and assessment. Journal of Dynamic Decision Making, 1, 1-13.

Fong, G. T., Krantz, D. H., \& Nisbett, R. E. (1986). The effects of statistical training on thinking about everyday problems. Cognitive Psychology, 18, 253-292. doi:10.1016/0010-0285(86)90001-0

Gary, M. S., Wood, R. E., \& Pillinger, T. (2012). Enhancing mental models, analogical transfer, and performance in strategic decision making. Strategic Management Journal, 33, 1229-1246. doi:10.1002/smj.1979

Gentner, D., \& Stevens, A. L. (1983). Mental models. Hillsdale, NJ: Lawrence Erlbaum.

Gick, M. L., \& Holyoak, K. J. (1980). Analogical problem solving. Cognitive Psychology, 12, 306-355. doi:10.1016/0010-0285(80)90013-4

Gick, M. L., \& Holyoak, K. J. (1987). The cognitive basis of knowledge transfer. In S. M. Cormier \& J. D. Hagman (Eds.), The educational technology series. Transfer of learning: Contemporary research and applications (pp. 9-46). San Diego, CA: Academic Press. doi:10.1016/B978-0-12-188950-0.50008-4

Gilson, L. L., Lim, H. S., Litchfield, R. C., \& Gilson, P. W. (2015). Creativity in teams: A key building block for innovation and entrepreneurship. In C. E. Shalley, M. A. Hitt, \& J. Zhou (Eds.), The Oxford handbook of creativity, innovation, and entrepreneurship (pp. 177-204). New York, NY: Oxford University Press.

Goldsmith, T. E., \& Kraiger, K. (1997). Applications of structural knowledge assessment to training evaluation. In J. K. Ford, S. W. J. Kozlowski, E. Salas, \& M. $\mathrm{S}$. Teachout (Eds.), Improving training effectiveness in work organizations (pp. 73-96). New York, NY: Lawrence Erlbaum.

Greiff, S., Fischer, A., Stadler, M., \& Wüstenberg, S. (2015). Assessing complex problem-solving skills with multiple complex systems. Thinking \& Reasoning, 21, 356-382. doi:10.1080/13546783.2014.989263

Hargadon, A. B., \& Bechky, B. A. (2006). When collections of creatives become creative collectives: A field study of problem solving at work. Organization Science, 17, 484-500. doi:10.1287/orsc. 1060.0200 
Hesketh, B. (1997). Dilemmas in training for transfer and retention. Applied Psychology, 46, 317-339. doi:10.1111/j.1464-0597.1997.tb01234.x

Hutchins, E. (1991). The social organization of distributed cognition. In L. B. Resnick, J. M. Levine, \& S. D. Teasley (Eds.), Perspectives on socially shared cognition (Vol. 13, pp. 283-307). Washington, DC: American Psychological Association.

Ivancic, I. V. K., \& Hesketh, B. (2000). Learning from errors in a driving simulation: Effects on driving skill and self-confidence. Ergonomics, 43, 1966-1984. doi:10.1080/00140130050201427

Jacobson, M. J., \& Spiro, R. J. (1995). Hypertext learning environments, cognitive flexibility, and the transfer of complex knowledge: An empirical investigation. Journal of Educational Computing Research, 12, 301-333. doi:10.2190/4T1BHBP0-3F7E-J4PN

Johnson-Laird, P. N. (1983). Mental models: Towards a cognitive science of language, inference, and consciousness. Cambridge, MA: Harvard University Press.

Jonassen, D. H. (1997). Instructional design models for well-structured and IIIstructured problem-solving learning outcomes. Educational Technology Research and Development, 45, 65-94. doi:10.1007/BF02299613

Jonassen, D. H., \& Grabinger, R. S. (1993). Applications of hypertext: Technologies for higher education. Journal of Computing in Higher Education, 4, 12-42. doi:10.1007/BF02941063

Kamouri, A. L., Kamouri, J., \& Smith, K. H. (1986). Training by exploration: Facilitating the transfer of procedural knowledge through analogical reasoning. International Journal of Man-Machine Studies, 24, 171-192. doi:10.1016/S00207373(86)80047-5

Kirschner, F., Paas, F., \& Kirschner, P. A. (2009). A cognitive load approach to collaborative learning: United brains for complex tasks. Educational Psychology Review, 21, 31-42. doi:10.1007/s10648-008-9095-2

Kirschner, P. A., Sweller, J., \& Clark, R. E. (2006). Why minimal guidance during instruction does not work: An analysis of the failure of constructivist, discovery, problem-based, experiential, and inquiry-based teaching. Educational Psychologist, 41, 75-86. doi:10.1207/s15326985ep4102_1

Klimoski, R., \& Mohammed, S. (1994). Team mental model: Construct or metaphor? Journal of Management, 20, 403-437. doi:10.1177/014920639402000206

Kozlowski, S. W. J., \& Bell, B. S. (2013). Work groups and teams in organizations: Review update. In N. Schmitt \& S. Highhouse (Eds.), Handbook of psychology: Vol. 12. Industrial and organizational psychology (2nd ed., pp. 412-469). Hoboken, NJ: Wiley.

Kraiger, K., Salas, E., \& Cannon-Bowers, J. A. (1995). Measuring knowledge organization as a method for assessing learning during training. Human Factors, 37, 804-816. doi:10.1518/001872095778995535

Laughlin, P. R., \& Barth, J. M. (1981). Group-to-individual and individual-to-group problem-solving transfer. Journal of Personality and Social Psychology, 41, 1087-1093. doi:10.1037/0022-3514.41.6.1087 
Laughlin, P. R., Carey, H. R., \& Kerr, N. L. (2008). Group-to-individual problem-solving transfer. Group Processes \& Intergroup Relations, 11, 319-330. doi:10.1177/1368430208090645

Laughlin, P. R., \& Sweeney, J. D. (1977). Individual-to-group and group-to-individual transfer in problem solving. Journal of Experimental Psychology, 3, 246-254. doi:10.1037/0278-7393.3.2.246

Lewis, K., Lange, D., \& Gillis, L. (2005). Transactive memory systems, learning, and learning transfer. Organization Science, 16, 581-598. doi:10.1287/ orsc. 1050.0143

Lima, M., Koehler, M. J., \& Spiro, R. J. (2004). Collaborative interactivity and integrated thinking in Brazilian business schools using cognitive flexibility hypertexts: The Panteon project. Journal of Educational Computing Research, 31, 371-406. doi:10.2190/TTK2-TDRP-D0DX-M8XN

Mathieu, J. E., Heffner, T. S., Goodwin, G. F., Salas, E., \& Cannon-Bowers, J. A. (2000). The influence of shared mental models on team process and performance. Journal of Applied Psychology, 85, 273-283. doi:10.1037/0021-9010.85.2.273

Mathieu, J. E., Maynard, M. T., Rapp, T., \& Gilson, L. (2008). Team effectiveness 1997-2007: A review of recent advancements and a glimpse into the future. Journal of Management, 34, 410-476. doi:10.1177/0149206308316061

Mayer, R. E. (2004). Should there be a three-strikes rule against pure discovery learning? American Psychologist, 59, 14-19. doi:10.1037/0003-066X.59.1.14

Maynard, D. C., \& Hakel, M. D. (1997). Effects of objective and subjective task complexity on performance. Human Performance, 10, 303-330. doi:10.1207/ s15327043hup1004_1

McClelland, G. H., \& Judd, C. M. (1993). Statistical difficulties of detecting interactions and moderator effects. Psychological Bulletin, 114, 376-390. doi:10.1037/0033-2909.114.2.376

McDaniel, M. A., \& Schlager, M. S. (1990). Discovery learning and transfer of problem-solving skills. Cognition and Instruction, 7, 129-159. doi:10.1207/ s1532690xci0702_3

Morris, C. D., Bransford, J. D., \& Franks, J. J. (1977). Levels of processing versus transfer appropriate processing. Journal of Verbal Learning and Verbal Behavior, 16, 519-533. doi:10.1016/S0022-5371(77)80016-9

Mumford, M. D., Supinski, E. P., Baughman, W. A., Constanza, D. P., \& Threlfall, K. V. (1997). Process-based measures of creative problem-solving skills: V. Overall prediction. Creativity Research Journal, 10, 73-85. doi:10.1207/ s15326934crj1001_8

Murdoch, B. B. (1957). Transfer designs and formulas. Psychological Bulletin, 54, 313-326. doi:10.1037/h0045180

October, J. (1990). Shared mental models and crew decision making (Tech. Report No. 46). Princeton, NJ: Cognitive Science Laboratory, Princeton University.

Oser, R. L., Gualtieri, J. W., Cannon-Bowers, J. A., \& Salas, E. (1999). Training team problem solving skills: An event-based approach. Computers in Human Behavior, 15, 441-462. doi:10.1016/S0747-5632(99)00031-X 
Paas, F. G., \& Van Merriënboer, J. J. (1994). Variability of worked examples and transfer of geometrical problem-solving skills: A cognitive-load approach. Journal of Educational Psychology, 86, 122-133. doi:10.1037/0022-0663.86.1.122

Paulus, P. B., \& Nijstad, B. A. (Eds.). (2003). Group creativity: Innovation through collaboration. New York, NY: Oxford University Press. doi:10.1093/acprof: oso/9780195147308.001.0001

Perkins, D. N., \& Grotzer, T. A. (1997). Teaching intelligence. American Psychologist, 52, 1125-1133. doi:10.1037/0003-066X.52.10.1125

Pinto, J. K., \& Prescott, J. E. (1990). Planning and tactical factors in the project implementation process. Journal of Management Studies, 27, 305-327. doi:10.1111/j.1467-6486.1990.tb00249.x

Prince, M. J., \& Felder, R. M. (2006). Inductive teaching and learning methods: Definitions, comparisons, and research bases. Journal of Engineering Education, 95, 123-138. doi:10.1002/j.2168-9830.2006.tb00884.x

Raudenbush, S. W., \& Bryk, A. S. (2002). Hierarchical linear models: Applications and data analysis methods. Thousand Oaks, CA: Sage.

Salomon, G., \& Perkins, D. N. (1989). Rocky roads to transfer: Rethinking mechanism of a neglected phenomenon. Educational Psychologist, 24, 113-142. doi:10.1207/s15326985ep2402_1

Schilling, M. A., Vidal, P., Ployhart, R. E., \& Marangoni, A. (2003). Learning by doing something else: Variation, relatedness, and the learning curve. Management Science, 49, 39-56. doi:10.1287/mnsc.49.1.39.12750

Schmidt, R. A., \& Bjork, R. A. (1992). New conceptualizations of practice: Common principles in three paradigms suggest new concepts for training. Psychological Science, 3, 207-217. doi:10.1111/j.1467-9280.1992.tb00029.x

Schwartz, D. L., \& Bransford, J. D. (1998). A time for telling. Cognition and Instruction, 16, 475-522. doi:10.1207/s1532690xci1604_4

Scott, G., Leritz, L. E., \& Mumford, M. D. (2004). The effectiveness of creativity training: A quantitative review. Creativity Research Journal, 16, 361-388. doi:10.1080/10400410409534549

Shalley, C. E., Zhou, J., \& Oldham, G. R. (2004). The effects of personal and contextual characteristics on creativity: Where should we go from here? Journal of Management, 30, 933-958. doi:10.1016/j.jm.2004.06.007

Shapiro, A., \& Niederhauser, D. (2004). Learning from hypertext: Research issues and findings. In D. H. Jonassen (Ed.), Handbook of research on educational communications and technology (2nd ed., pp. 605-620). Mahwah, NJ: Lawrence Erlbaum.

Simon, H. A. (1977). The structure of ill-structured problems. In H. A. Simon (Ed.), Models of discovery (pp. 304-325). Dordrecht, The Netherlands: Springer.

Skilton, P. F., \& Dooley, K. J. (2010). The effects of repeat collaboration on creative abrasion. Academy of Management Review, 35, 118-134. doi:10.5465/ AMR.2010.45577886

Spiro, R. J., Coulson, R. L., Feltovich, P. J., \& Anderson, D. K. (1988). Cognitive flexibility theory: Advanced knowledge acquisition in ill-structured domains 
(Technical Report No. 441). Champaign: University of Illinois at UrbanaChampaign.

Spiro, R. J., Feltovich, P. J., Jacobson, M. J., \& Coulson, R. L. (1991). Knowledge representation, content specification, and the development of skill in situationspecific knowledge assembly: Some constructivist issues as they relate to cognitive flexibility theory and hypertext. Educational Technology, 31, 22-25.

Spiro, R. J., \& Jehng, J. C. (1990). Cognitive flexibility and hypertext: Theory and technology for the nonlinear and multidimensional traversal of complex subject matter. In D. Nix \& R. Spiro (Eds.), Cognition, education, and multimedia: Exploring ideas in high technology (pp. 163-205). Hillsdale, NJ: Lawrence Erlbaum.

Spiro, R. J., Vispoel, W. P., Schmitz, J. G., Samarapungavan, A., Boerger, A. E., Britton, B. K., \& Glynn, S. M. (1987). Knowledge acquisition for application: Cognitive flexibility and transfer in complex content domains. In B. K. Britton \& S. M. Glynn (Eds.), Executive control processes (pp. 177-199). Hillsdale, NJ: Lawrence Erlbaum.

Stolovitch, H. D., \& Keeps, E. J. (1991). Selecting and writing case studies for improving human performance. Performance Improvement Quarterly, 4, 43-54. doi:10.1111/j.1937-8327.1991.tb00490.x

Thorndike, E. L. (1923). The influence of first-year Latin upon ability to read English. School \& Society, 17, 165-168.

Van Boxtel, C., Van der Linden, J., \& Kanselaar, G. (2000). Collaborative learning tasks and the elaboration of conceptual knowledge. Learning and Instruction, 10, 311-330. doi:10.1016/S0959-4752(00)00002-5

West, M. A. (2002). Sparkling fountains or stagnant ponds: An integrative model of creativity and innovation implementation in work groups. Applied Psychology, 51, 355-387. doi:10.1111/1464-0597.00951

West, M. A., \& Anderson, N. R. (1996). Innovation in top management teams. Journal of Applied Psychology, 81, 680-693. doi:10.1037/0021-9010.81.6.680

Wittgenstein, L. (1953). Philosophical investigations. New York, NY: Macmillan.

Zhou, J., \& Oldham, G. R. (2001). Enhancing creative performance: Effects of expected developmental assessment strategies and creative personality. The Journal of Creative Behavior, 35, 151-167. doi:10.1002/j.2162-6057.2001. tb01044.x

\section{Author Biographies}

Andra F. Toader is a postdoctoral researcher at the University of Konstanz in Germany. Her research interests center on teams, in particular cognition, adaptation, and creativity, and more recently on leadership, ethics, and self-regulation.

Thomas Kessler is a professor in social psychology at the Friedrich-Schiller University, Jena, Germany. His research focuses on group processes, group and identity formation, cooperation and conflict, as well as on prejudice and social discrimination. 